John A. Myburgh

\section{Reply to Oud}

Accepted: 27 March 2009

Published online: 15 April 2009

(C) Springer-Verlag 2009

This reply refers to the comment available at: doi:10.1007/s00134-009-1492-6.

On behalf of the CAT Study Investigators.

Sir: Our study was a relative effectiveness trial conducted under "real life" conditions to determine whether there was a difference in the time taken between epinephrine and norepinephrine to achieve a clinicianprescribed mean arterial pressure (MAP) objective in a heterogeneous population of critically ill patients. We did not prescribe haemodynamic monitoring or management strategies, which in the context of a pragmatic clinical study, is an established methodological approach, exemplified in the Saline vs Albumin Fluid Evaluation (SAFE) study [1]. We stipulated a default MAP goal of $70 \mathrm{mmHg}$ (unless directed by the attending clinicians) and defined achievement of this objective when study drug (in any dose) was not required for $24 \mathrm{~h}$. This reflects current practice in Australia, where catecholamines are widely used to defend pressure rather than being reserved for "rescue" therapies to treat shock.

This explains the two issues raised by Oud, viz the "remarkably long" time to attain target MAP and the comparatively low dose of study drug compared with the Annane study [2]. Restoration of target perfusion pressure was attained within $4 \mathrm{~h}$ with both drugs which is comparable with the Martin study [3] (Fig. 2); although the catecholamines were used to defend MAP for a longer period, this was the primary endpoint. This did not translate into differences between vasopressor-free days or organ failure scores.

We confirm that the doses of catecholamines were higher in patients with severe sepsis, although there was no difference in the time to attainment of target MAP for this prespecified subgroup.

We therefore do not agree with Oud's conclusion that our results do not represent "relevant practice" and submit that our study provides unique and substantive pharmacodynamic evidence about two ubiquitously used catecholamines in critically ill patients.

\section{References}

1. SAFE Study Investigators (2004) A comparison of albumin and saline for fluid resuscitation in the intensive care unit. N Engl J Med 350:2247-2256

2. Annane D, Vignon P, Renault A, Bollaert PE, Charpentier C, Martin C, Troché G, Ricard JD, Nitenberg G, Papazian L, Azoulay E, Bellissant E, CATS Study Group (2007)

Norepinephrine plus dobutamine versus epinephrine alone for management of septic shock: a randomised trial. Lancet 370:676-684

3. Martin C, Papazian L, Perrin G, Saux P, Gouin F (1993) Norepinephrine or dopamine for the treatment of hyperdynamic septic shock? Chest 103:1826-1831

J. A. Myburgh (৫) Intensive Care Medicine, The St George Hospital, Gray Street, Kogarah, Sydney, NSW 2217, Australia e-mail: j.myburgh@unsw.edu.au

Tel.: +61-2-93503373

Fax: +61-2-93503971 